\title{
Evaluation of tetracycline in milk following extra-label administration of topical tetracycline for digital dermatitis in dairy cattle
}

\author{
G. Cramer, ${ }^{1 *}$ L. Solano, ${ }^{2}$ and R. Johnson ${ }^{3}$ \\ ${ }^{1}$ Department of Veterinary Population Medicine, University of Minnesota, St. Paul 55108 \\ ${ }^{2}$ Farm Animal Care Associates, Calgary, Alberta, Canada, T2L 0T6 \\ ${ }^{3}$ Department of Biomedical Sciences, University of Guelph, Guelph, Ontario, Canada, N1G 2W1
}

\section{ABSTRACT}

Digital dermatitis (DD) is a painful infectious foot lesion commonly treated topically with extra-label tetracycline. Our objectives were to determine the concentrations of tetracycline in milk and plasma and to calculate a withdrawal interval following topical application at various doses. Another objective was to evaluate agreement between tests for measuring tetracycline in milk. A randomized block trial was conducted on 2 farms, where 50 cows with active DD lesions on 2 feet were allocated to 1 of 5 treatment groups $(\mathrm{n}=10$ cows per group). Treatment groups consisted of topical applications of tetracycline hydrochloride, in a paste or as a powdered form under a bandage, at 3 different dosing levels $(2,5$, and $25 \mathrm{~g})$ on each of the 2 affected feet. Following enrollment and treatment, samples were collected from milk, teat skin, and blood every 8 to $24 \mathrm{~h}$ for up to $7 \mathrm{~d}$ postdosing. Concentrations of tetracycline were measured by liquid chromatography-mass spectrometry and milk samples were further tested using the Charm ROSA TET test (Charm Sciences Inc., Lawrence, MA). Tetracycline was present in milk, plasma, and teat skin from all treatment groups. Tetracycline concentrations varied depending on time of sampling, method of application, and dosing level. At $8 \mathrm{~h}$ post-treatment, $11 \%$ of cows had tetracycline present in milk higher than 100 $\mathrm{ng} / \mathrm{mL}(\mathrm{ppb})$ but none higher than $300 \mathrm{ng} / \mathrm{mL}$. The 25-g treatment group had the longest estimated withdrawal interval, the highest observed concentrations (210-244 ng/mL) of tetracycline present in milk, and the longest observed consecutive period of tetracycline presence (from 8 to $72 \mathrm{~h}$ ) among all treatment groups. Compared with liquid chromatography-mass spectrometry, the Charm test had a sensitivity of 77 and $100 \%$ for measuring tetracycline in milk at $\geq 30$ and $\geq 100 \mathrm{ng} /$ $\mathrm{mL}$, respectively. Post-treatment samples of the teat skin were taken from 15 cows on 6 occasions, and every

Received April 20, 2018

Accepted September 13, 2018.

*Corresponding author: gcramer@umn.edu cow had tetracycline present in at least 1 of those 6 samples. This confirms an association between topical DD treatment with tetracycline and contamination of the teat. A total of $22 \%$ of blood samples had detectable tetracycline, and the majority (63\%) occurred at $8 \mathrm{~h}$ post-treatment. At $100 \mathrm{ng} / \mathrm{mL}$, the estimated cow-level milk withdrawal interval ranged from 0 to 70 h. At $300 \mathrm{ng} / \mathrm{mL}$, the estimated cow-level withdrawal interval ranged from 0 to $34 \mathrm{~h}$, and was $0 \mathrm{~h}$ at the bulk tank level. We recommend that conservative measures be adopted after extra-label use of topical tetracycline for DD treatment, including using a low dose and strategic post-treatment testing for tetracycline-class drugs in milk.

Key words: digital dermatitis, food safety, milk drug residues, withdrawal interval

\section{INTRODUCTION}

Digital dermatitis (DD) is a common infectious foot disease that causes ulcerative and painful lesions (Döpfer et al., 1997; Cutler et al., 2013). The reported prevalence of DD in Canada and Europe ranges from 24 to 28\% (Cramer et al., 2008; Solano et al., 2016; Oliveira et al., 2017); in the United States, DD accounted for almost 50\% of cases of lameness (USDA, 2009; DeFrain et al., 2013). The disease affects productivity (ArgáezRodríguez et al., 1997; Relun et al., 2013; Gomez et al., 2015), and financial losses associated with a case of DD are estimated at approximately US $\$ 133$ (Cha et al., 2010).

Digital dermatitis is a polybacterial disease, with Treponema spp. consistently present in DD lesions, and the gut microbiome considered an important reservoir of DD-related microbes (Zinicola et al., 2015). However, experimental challenge models have not been capable of consistently inducing typical DD lesions by inoculating pure cultures of DD-associated treponemes (Gomez et al., 2012; Krull et al., 2016b; Plummer and Krull, 2017). In addition, the development of effective vaccines have failed to protect cattle from the disease (Berry et al., 2004; Wilson-Welder et al., 2015). Thus, 
the exact etiology of DD is still debated, but scientific consensus exists on a bacterial origin (Plummer and Krull, 2017).

Historically, different antimicrobials and disinfecting agents have been used to treat DD lesions (Hernandez and Shearer, 2000; Moore et al., 2001; Holzhauer et al., 2011). In North America, DD is commonly treated with a single topical application of tetracycline directly to the lesion (Berry et al., 2010; Cutler et al., 2013; Apley, 2015). Tetracycline is commonly applied as a paste or in powdered form (with or without bandaging) at dose levels ranging from 2 to $25 \mathrm{~g}$ per affected foot. Furthermore, from a survey of almost 300 veterinarians and hoof trimmers in North America, the majority (45\%) reported routine topical application of tetracycline when treating other foot lesions, such as sole ulcers and abscesses (Kleinhenz, 2014). This use of topical tetracycline for treating foot lesions in food-producing animals is extra-label in North America. Extra-label drug use (ELDU) requires a valid veterinarian-clientpatient relationship and a written prescription, including information on dosing regimen, application method, and appropriate milk and meat withdrawal periods in accordance with the farm's treatment protocol (Health Canada and Veterinary Drugs Directorate, 2008; US Food and Drug Administration, 2010). To ensure food safety, regulatory agencies in Canada and Europe have set maximum residue limits (MRL) and tolerances in the United States to establish the maximum allowable level of residues that can safely remain in food products without posing a risk to human health. The Codex Alimentarius Commission and the European Union Commission Regulation have recommended MRL for tetracycline of $100 \mathrm{ng} / \mathrm{mL}$ (ppb) in cattle milk (European Medicines Agency and Committe for Medicinal Products for Veterinary Use, 2010; World Health Organization, 2015). The current MRL for tetracycline in dairy milk in Canada is $100 \mathrm{ng} / \mathrm{mL}$ (Health Canada and Veterinary Drugs Directorate, 2017), whereas in the United States the tolerance is $300 \mathrm{ng} / \mathrm{mL}$ (US Food and Drug Administration, 2010).

In the United States, there have been reports of quantifiable levels of tetracycline in milk samples purchased from supermarkets (Fritz and Zuo, 2007) and quantifiable oxytetracycline concentrations in milk following intrauterine therapy (Gorden et al., 2016). Studies from the Middle East have reported the presence of tetracycline higher than the allowable maximum levels $(100 \mathrm{ng} / \mathrm{mL})$ in pasteurized milk samples collected from markets (Al-Mazeedi et al., 2010; Mesgari Abbasi et al., 2011). Historically, the risk of violative antibiotic levels in milk following topical application of tetracycline for treatment of DD was considered minimal, and evidence of milk samples with presence of tetracycline is scarce (Britt et al., 1999; Cutler et al., 2013). For the treatment of DD, there are reports of tetracycline in plasma, synovial fluid, and milk following local and systemic intravenous administration (Rodrigues et al., 2010). For topical DD treatment with oxytetracycline, Britt et al. (1999) reported quantifiable concentrations of oxytetracycline in milk from 3.5 to $12 \mathrm{ng} / \mathrm{mL}$. Unfortunately, that study only evaluated a narrow range of doses (1,500-2,000 mg of oxytetracycline) and used a tetracycline formulation that is currently not widely used in the industry to treat DD. In another Canadian study, Cutler et al. (2013) evaluated the efficacy of 2 different treatments for DD and reported that no tetracycline was found when milk was tested on a small number of the treated cows.

Milk marketing boards and processing companies in North America have reported violative antibiotic levels in bulk tank milk after topical tetracycline administration for DD treatment (G. MacNaughton, Dairy Farmers of Ontario, Mississauga, ON, Canada; personal communication). Given that DD treatment with tetracycline is ELDU and limited data exist on the presence of antibiotics in milk with currently used drugs, doses, and dosages, there is a need to further evaluate topical tetracycline treatment for DD in dairy cattle. Our study will assist veterinarians with recommendations for extra-label use of topical tetracycline to treat DD in dairy cattle, thereby minimizing risks of violative levels in milk and promote safety of the human food supply.

The primary objective of our study was to determine the milk concentrations and withdrawal interval of tetracycline following topical application at various doses. Secondary objectives included (1) evaluation of the agreement between assays used to measure tetracycline in milk and (2) investigation of plasma concentrations of tetracycline following topical application of a high dose. Our hypothesis was that high doses of topical tetracycline in lactating cattle would be associated with higher concentrations of tetracycline in milk, that tetracycline would persist longer compared with cows treated with lower doses, and that this would result in a longer withdrawal interval.

\section{MATERIALS AND METHODS}

\section{Farm Selection}

A convenience sample of 2 dairy farms in Minnesota were recruited from an existing network of hoof trimmer and veterinary contacts. To be included in the study, these farms met the following participation criteria: a predominantly Holstein breed herd housed in freestalls, $\geq 10 \%$ prevalence of M2 lesions based on hoof trimming records, and infrequent foot bathing schedule. To en- 
sure farms had high DD prevalence, selected farms had $\geq 10 \%$ of cows with M2 lesions on multiple legs on an initial screening visit. Herd A was enrolled in December 2013 and had 700 lactating cows housed in stalls bedded with dried manure solids. Herd B was enrolled in August 2014 and had 300 lactating cows housed in sand-bedded stalls. Both herds were milked 3 times/d in a parallel milking parlor. All procedures were approved by the University of Minnesota Institutional Animal Care and Use Committee (1312-31180A) and University of Guelph Animal Care Committee (AUP 1914).

\section{Cow Selection and DD Lesion Assessment}

Before enrollment, cows were screened for the presence of DD on all feet during morning milking by 1 observer in each herd. Inspection of DD in the milking parlor has been described in detail (Cramer et al., 2018). Briefly, cows' feet were scored without prior washing or cleaning with the assistance of a flashlight. Cows were selected for further assessment if they had DD lesions on at least 2 feet. Diseased cows in the sick pen were excluded from the study.

Selected cows where then inspected in a hoof trimming chute (Comfort Hoof Care H series, Comfort Hoof Care, Baraboo, WI). All feet were cleaned and scored for DD by the first author using the modified M-stage scoring system according to Döpfer et al. (1997) and amended by Berry et al. (2012). In short, lesions were classified as M0 if skin was normal; M1 if a small ( $<2 \mathrm{~cm}$ in diameter), red-gray epithelial defect was observed; M2 if an acute, ulcerative (bright-red), or granulomatous (red-gray) lesion $\geq 2 \mathrm{~cm}$ in diameter, usually painful at touch, was present; M3 (healing stage) if lesion presented a dry brown and scab-like tissue; M4 (chronic stage) if the lesion had a dyskeratotic, thickened epithelium or proliferative growth; and M4.1 if the chronic stage of M4 had an M1 lesion within its perimeter. Cows with M2 lesions present in 2 feet were enrolled in the study (Figure 1). Cows in the hospital pen or with evidence of a recent hoof trim or treatment for DD were excluded even if M2 lesions were present on 2 feet. In both herds, the last hoof trimming visit occurred $>2$ wk before enrollment. Each farm's treatment records were also assessed to ensure that study cows had not received parental antibiotics in the past month.

\section{Study Design and Baseline Sample Collection}

This study was adapted from the recommendations outlined in the Veterinary International Cooperation on Harmonisation guideline no. 48 (US Food and Drug Administration and Center for Veterinary Medicine,

\section{Start of trial:}

1. DD screening at milking parlor

2. DD inspection at trimming chute

3. DD treatment allocation

\begin{tabular}{|c|c|c|c|c|c|c|c|c|c|c|c|c|}
\hline \multirow{2}{*}{\multicolumn{2}{|c|}{$\begin{array}{l}\text { Time post- } \\
\text { enrollment }\end{array}$}} & \multicolumn{3}{|c|}{$1 \mathrm{~d}$} & \multicolumn{2}{|c|}{$2 \mathrm{~d}$} & \multicolumn{2}{|c|}{$3 \mathbf{d}$} & \multirow{2}{*}{$\begin{array}{r}4 \mathrm{~d} \\
96 \mathrm{~h}\end{array}$} & \multirow{2}{*}{$\begin{array}{c}5 \mathrm{~d} \\
120 \mathrm{~h}\end{array}$} & \multirow{2}{*}{$\begin{array}{c}6 \mathrm{~d} \\
144 \mathrm{~h}\end{array}$} & \multirow{2}{*}{$\begin{array}{c}7 \mathrm{~d} \\
168 \mathrm{~h}\end{array}$} \\
\hline & & $0 \mathrm{~h}$ & $8 \mathrm{~h}$ & $24 \mathrm{~h}$ & $32 \mathrm{~h}$ & $48 \mathrm{~h}$ & $56 \mathrm{~h}$ & $72 \mathrm{~h}$ & & & & \\
\hline & Sample No. & 1 & 2 & 3 & 4 & 5 & 6 & 7 & 8 & 9 & 10 & 11 \\
\hline \multirow{3}{*}{ 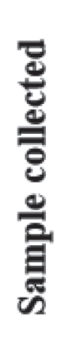 } & $\begin{array}{c}\text { Milk } \\
\text { (50 cows) }\end{array}$ & $\checkmark$ & $\checkmark$ & $\checkmark$ & $\checkmark$ & $\checkmark$ & $\checkmark$ & $\checkmark$ & $\checkmark$ & $\checkmark$ & $\checkmark$ & $\checkmark$ \\
\hline & $\begin{array}{c}\text { Teat wash } \\
\text { (15 cows) }\end{array}$ & $\checkmark$ & $\checkmark$ & $\checkmark$ & & $\checkmark$ & $\checkmark$ & $\checkmark$ & & & & \\
\hline & $\begin{array}{l}\text { Blood } \\
\text { (6 cows) }\end{array}$ & $\checkmark$ & $\checkmark$ & $\checkmark$ & & $\checkmark$ & & $\checkmark$ & & $\checkmark$ & & $\checkmark$ \\
\hline
\end{tabular}

Figure 1. Timeline of trial, showing inspection and sampling of cows treated for digital dermatitis (DD) with 3 different tetracycline doses $(2,5$, and $25 \mathrm{~g})$ and 2 different application methods (paste and powder). Only herd B was used for data on teat wash samples. Blood samples were collected only from the $25 \mathrm{~g}$ treatment group in herd B at 8, 24, 48, 72, 120, and $168 \mathrm{~h}$. 
2015). This guideline is used by Canadian and US regulatory agencies for the establishment of withdrawal periods for veterinary drugs approved for use in food producing animals, and recommends a sample size of 20 animals. In our study we used a convenience sample of 50 cows with 10 cows per treatment group.

\section{Baseline Samples}

At trial outset, during the initial milking or trimming chute inspection, composite foremilk samples as well as teat wash samples were taken of all cows with DD lesions. These samples were used as baseline to ensure tetracycline was not present before enrollment (Figure 1). Composite milk samples were collected after udder preparation using $60-\mathrm{mL}$ milk sampling containers (Thermo Scientific Capitol Vial, Thermo Fisher Scientific, Waltham, MA). Teat wash samples were collected before udder preparation and consisted of dipping each teat in 300-mL containers (Corning Snap Seal, Fisher Scientific Company, ON, Canada) filled with 100 to 150 $\mathrm{mL}$ of commercially sourced milk. Teat wash samples were collected to investigate the presence of tetracycline on the teat skin. As outlined above, cows were enrolled and samples collected in herd A before herd B. Milk bought from a commercial store was used for teat wash sample collection in herd A. Unfortunately, low tetracycline concentrations $(<10 \mathrm{ng} / \mathrm{mL})$ determined by liquid chromatography-tandem mass spectrometry (LC-MS/MS) were found during assay, resulting in the removal of these samples from the study. Reconstituted organic milk powder (Organic Valley, LaFarge, WI) was instead used in herd B for teat wash sample collection. Therefore, only teat wash samples collected from herd B were evaluated in the study. Organic milk powder was reconstituted according to label directions using distilled water (Premium Waters, Minneapolis, $\mathrm{MN}$ ), and tested for the presence of tetracycline before using LC-MS/MS.

\section{Randomization}

At trimming chute inspection on d 1 (Figure 1), cows with DD lesions present on 2 feet were enrolled in the study and randomly allocated to 1 of 5 treatment groups. A block randomization list was created in Microsoft Excel (v15.0, Microsoft Corp., Redmond, WA) using the random number generator. A number was assigned to each treatment to create an order for treatment allocation. The order of treatment used for the first 5 cows was repeated for the next 5 cows and so forth until all 50 cows were allocated to a treatment group. Once treatment allocation order was established, 3 cows were also randomly selected from each treatment group to have teat wash samples taken using the same random number generator.

\section{Treatments and Test Samples Collection}

The 5 treatment groups entailed 2 topical tetracycline hydrochloride delivery systems, specifically a paste (PST) and as a powdered form held under bandage (WRP) applied at 3 different dosing levels $(2,5$, and $25 \mathrm{~g}$ ) on each affected foot. The 25 -g dose was used in the WRP treatment group only due to technical challenges with mixing this amount of tetracycline powder into a paste. Each dose of tetracycline hydrochloride (Onycin 1000; Vetoquinol Canada Inc., Lavaltrie, QC, Canada) was weighed on a scale in the laboratory and placed in a sealed $60-\mathrm{mL}$ milk sampling container before administration. Treatment groups were labeled as 2WRP, 2PST, 5WRP, 5PST, and 25WRP. The PST treatments consisted of $4.5 \mathrm{~mL}$ of propylene glycol and $1.5 \mathrm{~mL}$ of water mixed with the corresponding prepared dose of tetracycline. For the PST treatments, $6 \mathrm{~mL}$ of the water-propylene glycol mixture was blended with the corresponding prepared dose of tetracycline. The PST treatments were applied directly to the lesion using a paintbrush after the lesion area was gently cleaned without creating further tissue damage. To avoid cross contamination between treatment groups, the paintbrush was cleaned between cows. The WRP treatments consisted of 2,5 , or $25 \mathrm{~g}$ of tetracycline as powder wrapped loosely under a bandage (Coflex, Andover Salisbury, MA), which was removed after 48 h (Figure 1).

Each cow had the same treatment applied to each foot with an M2 lesion. Treating 2 feet per cow was in line with our hypothesis that tetracycline concentrations were associated with the use of high doses. In that regard, cows in the $2 \mathrm{WRP}, 2 \mathrm{PST}, 5 \mathrm{WRP}, 5 \mathrm{PST}$, and 25 WRP treatment groups received a total of 4,4 , 10,10 , and $50 \mathrm{~g}$ of tetracycline, respectively. If $>1 \mathrm{M} 2$ lesion was observed on the same foot, the dose of antibiotic for that foot was distributed among the lesions.

Cows were marked with a laser-numbered leg band (Nasco, Fort Atkinson, WI) for easy identification after enrollment. Following enrollment and treatment, samples were collected from milk, teats, and blood up to $7 \mathrm{~d}$ postdosing according to the schedule provided in Figure 1. Composite milk samples were taken at 11 time points from enrolled cows in both herds, and teat wash samples were collected in from herd B at 6 time points. After collection, each sample was transferred in duplicate into both 2-mL (Sarsted, Inc., Newton, $\mathrm{NC}$ ) and 6-mL (Corning Life Sciences, Corning, NY) cryogenic vials and immediately frozen at $-20^{\circ} \mathrm{C}$. Once all samples were collected from each herd they were 
transferred from $-20^{\circ} \mathrm{C}$ storage into a $-80^{\circ} \mathrm{C}$ freezer until shipping for testing.

Blood samples were collected to investigate plasma concentrations of tetracycline in cows following topical tetracycline application. Blood samples were collected from the 25WRP treatment group from herd B only at $8,24,48,72,120$, and $168 \mathrm{~h}$ postdosing according to the schedule outlined in Figure 1. The blood sampling schedule was based on availability of resources, and we anticipated that tetracycline in blood would be associated with the highest dose group. All blood samples were taken using vacutainers with EDTA anticoagulant and immediately stored on ice. Plasma was subsequently separated into 2 equal aliquots and frozen in a similar manner as the milk samples.

It was not possible to blind study personnel to treatment allocation during the study given the 2 drug delivery systems used in the study and that cows in the 25WRP treatment group had to be identified for blood sample collection. All cows were re-evaluated in the hoof trimming chute at approximately $120 \mathrm{~h}$ postdosing to determine DD status and collect final blood samples.

\section{Assays}

Milk samples and teat wash samples were analyzed at the Laboratory Services Division of the University of Guelph. This laboratory is ISO-17025 accredited by the Standards Council of Canada and the Canadian Association for Laboratory Accreditation. Tetracycline concentrations in submitted samples were assayed according to the laboratory standard operating procedures for tetracycline using liquid chromatography (Agilent 1260, Agilent Technologies Canada Inc., Mississauga, ON, Canada) coupled with MS/MS (ABSciex 5500 Q Trap, Sciex, Concord, ON, Canada). The reported limit of detection (LOD) for the assay was $2.5 \mathrm{ng} /$ $\mathrm{mL}$ with a limit of quantification (LOQ) of $6 \mathrm{ng} / \mathrm{mL}$. Oxytetracycline (Sigma-Aldrich, St. Louis, MO) was used as an internal standard for the assay. Tetracycline (Sigma-Aldrich) calibration curves were prepared daily for each test sample run. Quality control samples were included in the test sample runs and were within a tolerance of $\pm 15 \%$ of the nominal value. Calibration curves exhibited a correlation coefficient exceeding 0.995 across the concentration range on all test runs, with coefficients of variation for the reference standards being $<15 \%$, and LOQ $<20 \%$.

All milk samples were also tested using a commercial tetracycline immunoassay, the Charm ROSA TET test (Charm Sciences Inc., Lawrence, MA), and accompanying equipment and operating instructions (Charm Sciences Inc., 2013). At the time of funding, this was the test commonly used by Ontario's milk regulatory body. At the time of the study, the Charm ROSA TET test was validated with a range of detection for tetracycline from 10 to $30 \mathrm{ng} / \mathrm{mL}$. The test was run by the Laboratory Services Division of the University of Guelph according to the operator's manual (Charm Sciences Inc., 2013).

Plasma samples were tested for tetracycline at the Veterinary Diagnostics Laboratory, Iowa State University (Ames) using LC-MS/MS (Surveyor Pump and Autosampler and TSQ Discovery Max, Thermo Scientific, San Jose, CA). Tetracycline (Sigma-Aldrich) calibration curves exhibited a correlation coefficient exceeding 0.995 across the concentration range on all test sample runs, with coefficients of variation for the tetracycline reference standards, including $\mathrm{LOQ}$, at $<15 \%$. The assay's reported LOD was $1.5 \mathrm{ng} / \mathrm{mL}$ with the LOQ at 5 $\mathrm{ng} / \mathrm{mL}$. Demeclocycline (Thermo Fisher Scientific) was used as an internal standard. Quality control samples were included in the test sample runs and were within a tolerance of $\pm 15 \%$ of the nominal value.

\section{Data Management and Statistical Analyses}

Data were recorded on paper on farm and transferred to an Excel spreadsheet (Microsoft Corp.). Descriptive statistics and graphical data analysis occurred in STATA 14 (STATA Corp., College Station, TX).

\section{Test Agreement Analyses}

Cohen's kappa statistic, sensitivity, and specificity were calculated to determine level of agreement between the LC-MS/MS and the Charm ROSA TET test. The LC-MS/MS result was used as the gold standard. Agreement with LC-MS/MS results were calculated at 3 cutoff values using the lower $(10 \mathrm{ng} / \mathrm{mL})$ and upper (30 ng/mL) detection limit of the Charm ROSA TET test and the Canadian MRL (100 ng/mL). Cohen's kappa measured the agreement beyond chance and was calculated as (observed agreement - expected agreement $) /(1$ - expected agreement $)$ and was interpreted according to the following guidelines: $\leq 0=$ poor agreement, 0.01 to $0.2=$ slight, 0.21 to $0.4=$ fair, 0.41 to $0.6=$ moderate, 0.61 to $0.80=$ substantial, 0.81 to 1.0 = almost perfect agreement (Dohoo et al., 2009). Sensitivity was defined as the proportion of samples above each cutoff value of tetracycline as measured by LC-MS/MS that the Charm ROSA TET test identified as positive. Specificity was defined as the proportion of samples with no tetracycline $(<\mathrm{LOD})$ measured by LC-MS/MS that the Charm ROSA TET test identified as negative. 


\section{Withdrawal Interval Estimation}

The analyses used to estimate tetracycline milk withdrawal intervals were done according to US FDA guidelines and software library (Martinez et al., 2000; US Food and Drug Administration and Center for Veterinary Medicine, 2016) for establishing withdrawal intervals, which required the use of RStudio 1.0.143 (RStudio Inc., Boston, MA) running R 3.4.0 (R Core Team, Vienna, Austria). Briefly, a 99th percentile statistical tolerance limit with $95 \%$ confidence was used to determine withdrawal intervals. Statistical tolerance limits were calculated from linear regression models of the natural logarithmic values of the milk LC-MS/ MS test results (Martinez et al., 2000; De Gryze et al., 2007). This method allowed for estimation of a withdrawal interval where $99 \%$ of samples were below the statistical tolerance limit with a confidence of $95 \%$. Linear regression models were created separately for each treatment group. A value of $3 \mathrm{ng} / \mathrm{mL}$ (half of the assay LOQ) was assigned to all test results with reported values higher than the assay LOD, but lower than the LOQ, according to European guidelines (European Medicines Agency and Committe for Medicinal Products for Veterinary Use, 2016). To allow for the natural logarithmic transformation of results, a value of $1 \mathrm{ng} / \mathrm{mL}$ was assigned to all reported values $<\mathrm{LOD}$. As described by US Food and Drug Administration and Center for Veterinary Medicine (2016), the determination of an appropriate withdrawal interval is a decision analysis and not a search for perfect statistical fit of the data. Initially, models were created that included all post-treatment sampling time points. As our data included several values $<\mathrm{LOD}$ at $>48 \mathrm{~h}$, a decision analysis was performed. The process for this decision analysis consisted of sequentially creating linear models that included fewer sampling time points $>48 \mathrm{~h}$. From these models, the statistical prediction and tolerance limits were evaluated graphically. The final model chosen for withdrawal time estimation included the most sampling time points and had no observed values that were plotted above the estimated prediction interval. This approach ensures a more conservative estimate of the withdrawal interval than including data from all sampling time points. Withdrawal intervals were estimated for 10 (i.e., lower LOD of the Charm ROSA TET test), 100, and $300 \mathrm{ng} / \mathrm{mL}$ of tetracycline at the individual cow level and 10 and $300 \mathrm{ng} / \mathrm{mL}$ of tetracycline at the bulk tank level. For the calculation of bulk tank milk withdrawal interval (applicable to the United States only), a 10-cow herd size was assumed and LC-MS/MS results were divided by 10 as described in US Food and Drug Administration and Center for Veterinary Medicine (2016).

\section{RESULTS}

Fifty cows were enrolled in the study (10 cows per treatment group). One cow in each treatment group had tetracycline present in the baseline milk sample at enrollment. Data from these 5 cows were removed from the study, resulting in a total of 45 cows with data postenrollment (9 cows per treatment group). Three cows were not present during milking at various sample time points, resulting in 7 additional missed samples. A total of 488 milk, 90 teat, and 42 blood samples were collected. One milk sample was unsuitable for evaluation with the Charm ROSA TET test due to presence of clots. Another milk sample was lost for evaluation with LC-MS/MS. In total, data were obtained from 487 milk samples postenrollment. A total of 100 feet (20 feet per treatment group) with an M2 lesion were enrolled and treated. At re-evaluation $(120 \mathrm{~h}), 94$ of these lesions transitioned to an M3, M4 or M4.1 lesion. The remaining 6 lesions that did not transition from an M2 lesion were in the $5 \operatorname{PST}(\mathrm{n}=1), 2 \mathrm{PST}(\mathrm{n}=2)$, and $25 \mathrm{WRP}(\mathrm{n}=3)$ treatment groups.

\section{Post-Treatment Samples}

Milk Samples: LC-MS/MS. At $8 \mathrm{~h}$ post-treatment, $5 / 45$ cows $(11 \%)$ had tetracycline concentrations higher than the Canadian MRL (range $=120$ to 244 $\mathrm{ng} / \mathrm{mL}$ ), but none higher than the US tolerance. Three of these 5 cows were in the 25WRP treatment group, 1 in the $2 \mathrm{WRP}$ treatment group, and 1 in the 2PST treatment group. A total of $105(22 \%)$ samples from all treatment groups had tetracycline present throughout the sampling period, $80 \%$ of which occurred within 48 $\mathrm{h}$ following treatment. However, $70(67 \%)$ of the 105 samples with tetracycline present had tetracycline concentrations lower than the LOQ of $\leq 6 \mathrm{ng} / \mathrm{mL}$ (Figure 2).

Milk Samples: Charm ROSA TET Test. Of the 487 milk samples tested with the Charm ROSA TET test, 13 were positive, 9 of which occurred at 8 h post-treatment. A total of 6,4 , and 3 of these positive samples were in the 25WRP, $2 \mathrm{WRP}$, and $2 \mathrm{PST}$ treatment groups, respectively. One cow in the $25 \mathrm{WRP}$ treatment group had 3 consecutive positive results at 24,32 , and $48 \mathrm{~h}$. One cow in the 2PST group had a positive result at $168 \mathrm{~h}$ only. All positive samples on the Charm ROSA TET test had quantifiable (>LOQ) concentrations of tetracycline as determined by LCMS/MS, ranging from 9.4 to $230 \mathrm{ng} / \mathrm{mL}$. Agreement between Charm ROSA TET test and LC-MS/MS was substantial. The Charm ROSA TET test had a sensitivity of 50 to $78 \%$ and specificity of $99 \%$ for measuring tetracycline concentrations $\geq 10$ and $\geq 30 \mathrm{ng} / \mathrm{mL}$. Sen- 
Table 1. Agreement, sensitivity, and specificity estimates of the Charm ROSA TET test (Charm Sciences Inc., Lawrence, MA) for measuring tetracycline in milk with liquid chromatography-MS/MS as the gold standard $(\mathrm{n}=486$ milk samples $)$

\begin{tabular}{lccc}
\hline $\begin{array}{l}\text { Tetracycline } \\
\text { concentration }(\mathrm{ng} / \mathrm{mL})^{1}\end{array}$ & $\begin{array}{c}\text { Kappa } \\
(95 \% \mathrm{CI})\end{array}$ & $\begin{array}{c}\text { Sensitivity } \\
(95 \% \mathrm{CI})^{2}\end{array}$ & $\begin{array}{c}\text { Specificity } \\
(95 \% \mathrm{CI})^{3}\end{array}$ \\
\hline$\geq 10$ & $0.6(0.5-0.8)$ & $50.0(29.1-70.9)$ & $99.8(98.9-100.0)$ \\
$\geq 30$ & $0.6(0.4-0.9)$ & $77.8(40.0-97.2)$ & $98.7(97.3-99.5)$ \\
$\geq 100$ & $0.5(0.2-0.6)$ & $100.0(39.8-100)$ & $98.1(96.5-99.1)$ \\
\hline
\end{tabular}

${ }^{1}$ Set at Charm ROSA TET test's detection range of 10 to $30 \mathrm{ng} / \mathrm{mL}$ and the Canadian maximum residue limit of $100 \mathrm{ng} / \mathrm{mL}$ for tetracycline.

${ }^{2}$ Sensitivity $=$ proportion of samples above each cutoff value of tetracycline as measured by liquid chromatography-MS/MS that the Charm ROSA TET test identified as positive.

${ }^{3}$ Specificity = proportion of samples with no tetracycline (lower than limit of detection) measured by liquid chromatography-MS/MS that the Charm ROSA TET test identified as negative.

sitivity increased to $100 \%$ for measuring tetracycline concentrations $\geq 100 \mathrm{ng} / \mathrm{mL}$ (Table 1 ).

Teat Wash Samples: LC-MS/MS. Of the 15 cows tested for tetracycline in teat wash samples across 5 time points ( $\mathrm{n}=75$ samples $), 3$ samples were missed at the 72 -h time point. The missed samples were instead taken at $96 \mathrm{~h}$ but had no tetracycline measured at that time point. The 3 cows were in the $25 \mathrm{WRP}$, 5WRP, and 5PST treatment groups.
Tetracycline concentrations ranged from 7 to $210 \mathrm{ng} /$ $\mathrm{mL}$ and were found up to $72 \mathrm{~h}$ in all treatment groups. Three (4\%) teat wash samples from 2 cows in the 25WRP and 2PST treatment groups had tetracycline concentrations higher than $100 \mathrm{ng} / \mathrm{mL}$ at 8 and $24 \mathrm{~h}$. A total of $55(73 \%)$ and $36(48 \%)$ samples had tetracycline concentrations higher than the LOD and LOQ, respectively (Table 2 ). Twenty $(36 \%)$ of the 55 teat wash samples with tetracycline concentrations higher

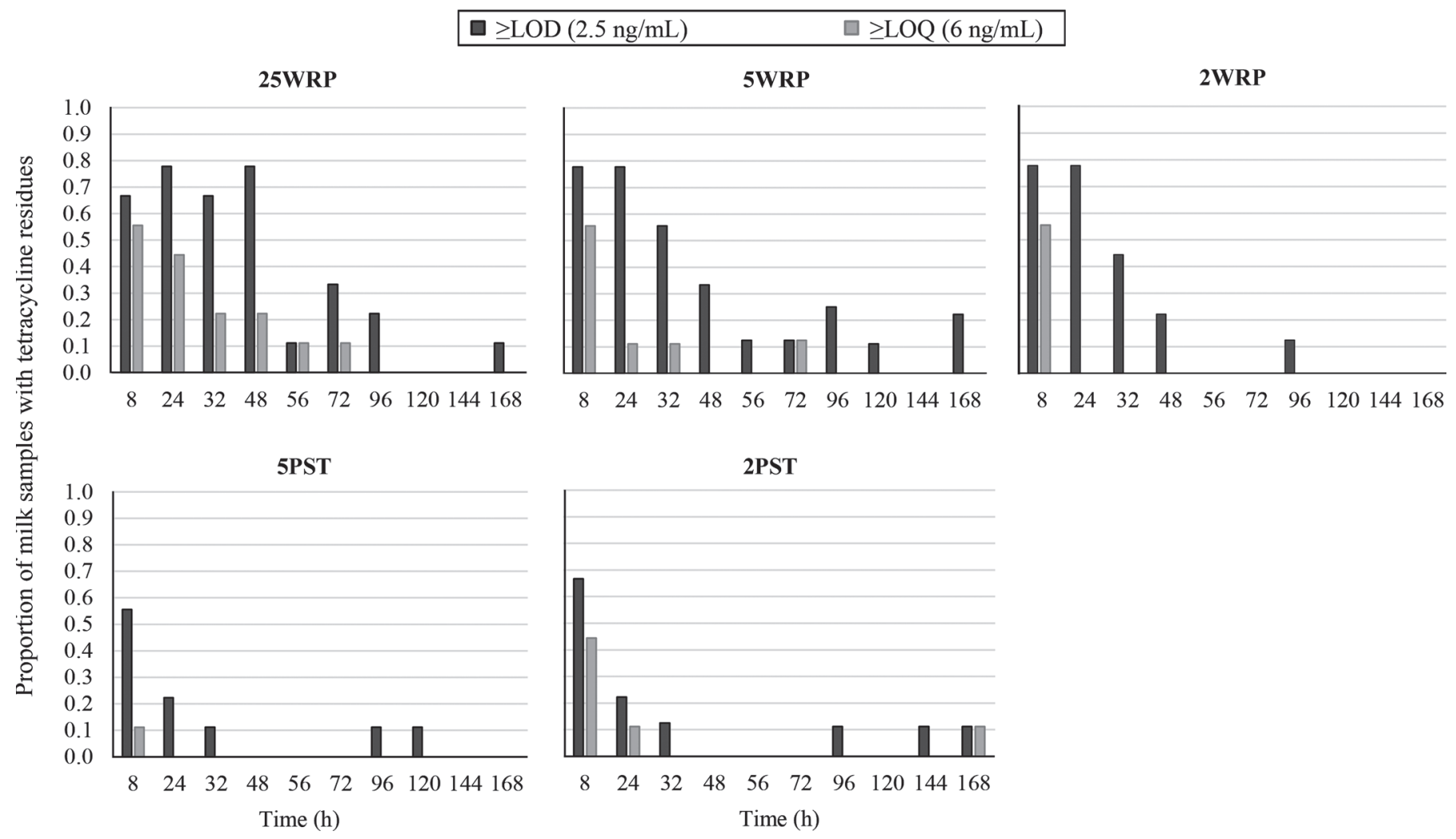

Figure 2. Distribution of milk samples $(\mathrm{n}=487)$ with tetracycline concentrations higher than the limit of detection (LOD) and limit of quantification (LOQ) following topical treatment for digital dermatitis. The 5 treatment groups entailed 2 topical tetracycline hydrochloride delivery systems, specifically a paste (PST) and as a powdered form held under bandage (WRP) applied at different dosing levels $(2,5$, and 25 g) on each of the 2 affected feet per cow. 
Table 2. Comparison (no., \% in parentheses) of tetracycline in all teat wash samples from 15 cows and corresponding milk samples using liquid chromatography-MS/MS and considering a limit of detection of $2.5 \mathrm{ng} / \mathrm{mL}$

\begin{tabular}{lccc}
\hline & \multicolumn{2}{c}{ Milk samples } & \\
\cline { 2 - 3 } Teat wash & \multicolumn{1}{c}{ Below } & Above & Total \\
\hline Below & $18(34)$ & $2(9)$ & 20 \\
Above & $35(66)$ & $20(91)$ & 55 \\
Total & 53 & 22 & 75 \\
\hline
\end{tabular}

than the LOD had corresponding milk samples with tetracycline present, as measured by LC-MS/MS. Two $(10 \%)$ of the 20 teat wash samples with no tetracycline had corresponding milk samples with tetracycline concentrations higher than the LOD, as measured by LC-MS/MS (Table 2).

Blood Samples: LC-MS/MS. Five of the 6 cows sampled for blood at 6 time points $(\mathrm{n}=36$ samples) had tetracycline present at $8 \mathrm{~h}$. One of these 5 cows continued to have tetracycline present at $24 \mathrm{~h}$, and another cow at 24 and $48 \mathrm{~h}$. However, these 8 blood samples with tetracycline present had plasma concentrations lower than the assay LOQ. The cow with tetracycline present on 3 consecutive blood samples (at 8, 24, and $48 \mathrm{~h}$ ) had corresponding milk samples with detectable (>LOD) tetracycline concentrations based on LC-MS/ MS. Three of the 5 cows with detectable tetracycline concentrations in blood at $8 \mathrm{~h}$ had corresponding milk samples with no tetracycline $(<\mathrm{LOD})$. Two of the 5 cows with tetracycline in their blood had corresponding milk samples with quantifiable (>LOQ) concentrations of tetracycline (6 and $230 \mathrm{ng} / \mathrm{mL}$ ). One cow with no tetracycline present in blood at $8 \mathrm{~h}$ had a corresponding milk and a teat wash sample with tetracycline concentrations of $210 \mathrm{ng} / \mathrm{mL}$ each.

\section{Withdrawal Interval Estimate}

At the cow level, for the 25WRP treatment group, withdrawal estimates for tetracycline using the Canadian MRL (100 ng/mL) and the US tolerance (300 ng/ $\mathrm{mL}$ ) were 70 and $34 \mathrm{~h}$ postdosing, respectively (Table 3). At the bulk tank level (using a 10-cow dilution factor; applicable to the United States only), for the $25 \mathrm{WRP}$ treatment group, tetracycline concentrations below 10 and $300 \mathrm{ng} / \mathrm{mL}$ in milk would be reached at 70 and $0 \mathrm{~h}$, respectively. Figure 3 illustrates the decision process that was used to establish the time periods to be included in the withdrawal interval estimation. Withdrawal intervals for the 2PST, 2WRP, and 5PST were based on samples taken $<48 \mathrm{~h}$. The $25 \mathrm{WRP}$ and $5 \mathrm{WRP}$ withdrawal interval calculations were based on samples taken $<72$ and $<120 \mathrm{~h}$, respectively.

\section{DISCUSSION}

Our study demonstrated the presence of tetracycline in milk, plasma, and teat skin up to $7 \mathrm{~d}$ following topical DD treatment. Tetracycline was present regardless of method of application or dosing level; however, $<5 \%$ of all samples had tetracycline concentrations higher than $100 \mathrm{ng} / \mathrm{mL}$ and none higher than $300 \mathrm{ng} / \mathrm{mL}$. The diagnostic sensitivity of the Charm ROSA TET test for measuring tetracycline in milk at $\leq 30 \mathrm{ng} / \mathrm{mL}$ was generally low but was highly accurate for measuring tetracycline at $\geq 100 \mathrm{ng} / \mathrm{mL}$. At the Canadian MRL of $100 \mathrm{ng} / \mathrm{mL}$, the estimated cow-level milk withdrawal

Table 3. Withdrawal interval (h) estimation using a 99th percentile statistical tolerance limit with $95 \%$ confidence, based on linear regression models from data of 9 cows per treatment group sampled every 8-12 h

\begin{tabular}{|c|c|c|c|c|c|c|}
\hline \multirow{3}{*}{$\begin{array}{l}\text { Treatment } \\
\text { group }^{1}\end{array}$} & \multirow{3}{*}{$\begin{array}{l}\text { Sampling } \\
\text { period }(\mathrm{h})\end{array}$} & \multicolumn{5}{|c|}{ Withdrawal interval (h) } \\
\hline & & \multicolumn{3}{|c|}{$\begin{array}{c}\text { Cow level }^{2} \\
(\mathrm{ng} / \mathrm{mL})\end{array}$} & \multicolumn{2}{|c|}{$\begin{array}{c}\text { Bulk tank } \\
\text { level }(\mathrm{ng} / \mathrm{mL})\end{array}$} \\
\hline & & 10 & 100 & 300 & 10 & 300 \\
\hline $25 \mathrm{WRP}$ & $<72$ & 175 & 70 & 34 & 70 & 0 \\
\hline $5 \mathrm{WRP}$ & $<120$ & 101 & 0 & 0 & 0 & 0 \\
\hline 5 PST & $<48$ & 34 & 0 & 0 & 0 & 0 \\
\hline $2 \mathrm{WRP}$ & $<48$ & 77 & 26 & 12 & 9 & 0 \\
\hline 2 PST & $<48$ & 66 & 19 & 0 & 19 & 0 \\
\hline
\end{tabular}


interval ranged from 0 to $70 \mathrm{~h}$, depending on dose level. At the US tolerance of $300 \mathrm{ng} / \mathrm{mL}$, the estimated cow-level withdrawal interval ranged from 0 to $34 \mathrm{~h}$, depending on dose level, and was $0 \mathrm{~h}$ at the bulk tank level.

Treatment of DD with tetracycline was effective in its ability to transition M2 lesions to nonactive (M3, M4, M4.1) lesions 5 d post-treatment. Clinical cure was not achieved at this point in time, as not a single lesion transitioned to the completely healed stage (M0), which is unlikely to have occurred by $5 \mathrm{~d}$
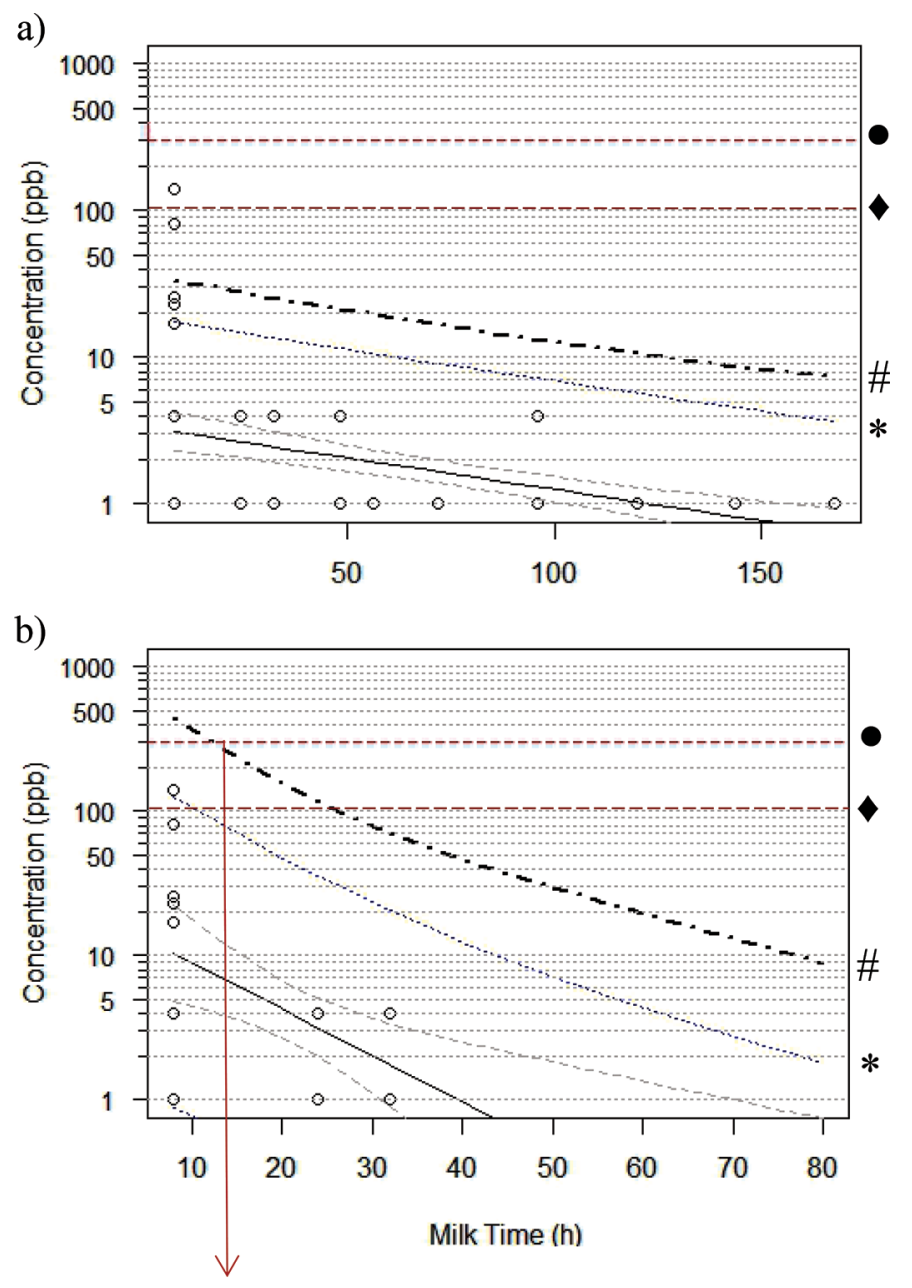

Withdrawal period is about $14 \mathrm{~h}$

Figure 3. Graphical representation example of the regression model and allowable tetracycline concentrations used to predict withdrawal interval for the treatment group that received a 2-g dose of tetracycline hydrochloride in a powdered form held under a bandage. (a) Model and tolerance including data from all the sampling periods, and (b) model and tolerance including sampling data from sampling periods $\leq 48 \mathrm{~h}$. Filled circles $(\bullet)$ represent US tolerance of tetracycline $(300 \mathrm{ng} / \mathrm{mL})$, a diamond $(\downarrow)$ represents Canadian maximum residue limit of tetracycline $(100 \mathrm{ng} / \mathrm{mL})$, a hash mark (\#) represents the $99 \mathrm{th}$ percentile tolerance band of $95 \%$ prediction band, and an asterisk $\left(^{*}\right)$ represents the $95 \%$ prediction band for linear model. post-treatment (Krull et al., 2016a). Studies that followed DD lesion progression for longer periods reported clinical cure rates ranging from 50 to $87 \%$ over 12 to 32 d after initial treatment with tetracycline-class drugs (Manske et al., 2002; Berry et al., 2010; Cutler et al., 2013). However, post-treatment observation periods up to $120 \mathrm{~d}$ are necessary to effectively evaluate cure and recrudescence of DD lesions (Krull et al., 2016a). Therefore, it is important to highlight that evaluating the therapeutic effectiveness of tetracycline for DD treatment was out of the scope of the current study, and conclusions on this subject cannot be drawn from our data.

Given the growing concerns with public health over antimicrobial use in food-producing animals and presence of tetracycline in marketed milk (Fritz and Zuo, 2007), dairy regulators in North America are incorporating screening programs for tetracycline-class drugs (Dairy Farmers of Ontario, 2017; National Conference on Interstate Milk Shipments, 2017). However, routine testing of all milk for tetracycline-class drugs is not yet mandatory, and practices vary among jurisdictions and dairy processors.

The Charm ROSA TET test used in the present study is a commercial, rapid screening immunoassay, intended to test positive for tetracycline in the concentration range of 10 to $30 \mathrm{ng} / \mathrm{mL}$ and above in commingled bulk tank milk (Charm Sciences Inc., 2013). Although used commonly to test milk from individual cows, the test is not validated for cow-side use. However, as the Charm test is not a microbial inhibition test, it seems unlikely these tests would differ when used on milk samples from individual cows versus commingled milk from the bulk tank (Sischo, 1996; Kang et al., 2005). When compared with our LC-MS/MS results, the sensitivity of the Charm ROSA TET test for tetracycline concentrations between 10 and $30 \mathrm{ng} /$ $\mathrm{mL}$ was low (50-70\%); however, at tetracycline concentrations above $100 \mathrm{ng} / \mathrm{mL}$, sensitivity was of $100 \%$. Comparison of test characteristics to those obtained in other studies is challenging due to use of differing screening tests [e.g., Charm II Test for tetracycline (Anderson et al., 1995; Gorden et al., 2016), or Charm II 6700 system (Al-Mazeedi et al., 2010)]. In addition, comparison is difficult because not all studies evaluated similar diagnostic test characteristics (Anderson et al., 1995) or only compared Charm-positive or suspected positive samples to a gold standard (LC-MS/MS; AlMazeedi et al., 2010). Based on our findings, the Charm ROSA TET test is an adequate and reliable test for tetracycline concentrations above the Canadian MRL of $100 \mathrm{ng} / \mathrm{mL}$ for tetracycline in dairy milk. However, it should be noted that milk containing tetracycline below the Canadian MRL, but greater than 10 to $30 \mathrm{ng} /$ 
$\mathrm{mL}$, will test positive with the Charm ROSA TET test and potentially be rejected at the processors discretion, regardless of being deemed safe for human consumption by regulatory agencies.

Our hypothesis that higher concentrations and longer durations of tetracycline in milk were associated with high dosing levels of tetracycline was supported by the longer estimated withdrawal intervals in the $25 \mathrm{WRP}$ group. Based on LC-MS/MS findings, the treatment group with the highest dose of tetracycline (25WRP) had antibiotic present for the longest consecutive period (from 8 to $72 \mathrm{~h}$ ) and reported the highest concentrations $(210-244 \mathrm{ng} / \mathrm{mL})$ among all treatment groups. However, our sample size was limited ( $\mathrm{n}=45$ cows) in all treatment groups and tetracycline was present in milk in all treatment groups and at various sampling times. Compared with the 25WRP group, even the lowest dosing group ( $2 \mathrm{~g}$ ) had higher than expected concentrations of tetracycline $(120-140 \mathrm{ng} / \mathrm{mL})$ and a shorter estimated withdrawal interval. As only the highest dose levels of tetracycline resulted in higher milk tetracycline concentrations and longer estimated withdrawal intervals, the risk for antibiotic residues appears not be dose-dependent at lower dose levels. To investigate the relationship between dose levels and residue time and duration, additional studies using larger sample sizes in multiple environments are necessary.

In the present study, tetracycline was present in $22 \%$ of all milk samples, but only $1 \%$ of all milk samples had concentrations higher than the Canadian MRL of 100 $\mathrm{ng} / \mathrm{mL}$. Tetracycline-class drug residues higher than $100 \mathrm{ng} / \mathrm{mL}$ have been reported in milk samples after intravenous, intramuscular, subcutaneous, and intrauterine administration (Anderson et al., 1995; Gorden et al., 2016). A study by Rodrigues et al. (2010) on 12 cows reported mean milk tetracycline concentrations from 0.1 to $6.2 \mathrm{ng} / \mathrm{mL}$ at 8 to $120 \mathrm{~h}$ following DD treatment with tetracycline. However, our results are not comparable with that study, as tetracycline was administered by a single intravenous or intravenous regional injection. Only 2 studies have evaluated presence of tetracycline (Cutler et al., 2013) or oxytetracycline (Britt et al., 1999) in milk after topical DD treatment, but neither study reported residues above $100 \mathrm{ng} / \mathrm{mL}$. Britt et al. (1999) reported that $12 \%$ of the milk samples contained oxytetracycline, whereas Cutler et al. (2013) did not report specific numbers. Apparent differences in findings of high tetracycline concentrations among studies could be a consequence of sample size, testing technology (e.g., MPLC vs. LC-MS/MS), LOD of the test (e.g., 3.3 vs. $2 \mathrm{ng} / \mathrm{mL}$ ), or the stage of the DD lesion in which the treatment was applied. Additionally, differences could also be due to the use of different antibiotics (oxytetracycline or tetracycline), topical drug delivery system (e.g., spray, bandage, paste), dose (e.g., $1.5 \mathrm{~g}$ of oxytetracycline vs. 2-25 g of tetracycline), and dosage (e.g., twice daily for $7 \mathrm{~d}$ vs. 1 time).

Evaluation of teat wash samples was intended to investigate presence of tetracycline on the cow teat skin, as analyzed by LC-MS/MS. The majority (73\%) of teat wash samples collected post-treatment had tetracycline present, and a small portion (4\%) of samples had tetracycline concentrations higher than $100 \mathrm{ng} /$ $\mathrm{mL}$. Moreover, most $(67 \%)$ of these samples were from the $25 \mathrm{WRP}$ treatment group. These findings indicate an association between administration of topical tetracycline for DD and presence of tetracycline in the cows' teat skin. It is possible that the source of tetracycline in milk may include external contact of antibiotic-treated feet with the udder and teat skin. Teat contamination with tetracycline may originate from direct contact of the udder with treated feet or with antibiotic present in the lying surface, or from contact of the udder with milk containing tetracycline (i.e., leaking cows that contaminate the lying surface).

Reporting tetracycline concentrations measured in the blood was of notable interest. It is anticipated that, after absorption following extravascular, oral, uterine, or intramammary routes of administration, tetracycline will distribute widely and quickly in the body, reaching low concentrations in plasma (Rodrigues et al., 2010; Gorden et al., 2016). However, we were not able to find relevant information regarding the absorption, distribution, and excretion of antibiotics when administered topically for lameness therapy in dairy cattle (Fajt and Apley, 2001). To our knowledge, ours is the first study to report tetracycline in the blood after topical treatment for DD.

Currently, the Food Animal Residue Avoidance Databank (FARAD) in the United States recommends a 24-h milk withdrawal interval for topical use of tetracycline provided no oral ingestion occurs (FARAD, 2018). The recommendation by FARAD also references articles that suggested a zero-day milk withdrawal when topical tetracycline-class drugs are used in dairy cattle (Baynes et al., 1997; Martin-Jimenez et al., 1997). Although it is unclear how the withdrawal interval for topical use of tetracycline in dairy cattle was determined by FARAD, there are guidelines for the extrapolation of withdrawal intervals from available pharmacokinetic data (Riviere et al., 1998). It is important to note that the maximum allowable limits for drugs in edible products from foodproducing animals, and official withdrawal times, are the responsibility of regulatory agencies in each country. Differences with maximum allowable drug limits between countries are due to many factors, including the accepted percentage of the average daily intake for the drug in milk, standard number of milkings per cow 
per day and average herd size, and data analysis approaches, including dilution factors, used in the final estimation of the withdrawal interval. Any recommendation of withdrawal intervals following topical extralabel tetracycline use in lactating dairy cattle should also include testing milk from individual treated cows for the presence of violative tetracycline levels before allowing that milk to enter the bulk tank.

For our analysis, only including time points with a high proportion of milk samples with tetracycline concentrations > LOD resulted in a more appropriate and conservative withdrawal interval estimation. Results on the determination of withdrawal interval varied depending on the maximum allowable concentrations used (i.e., $100 \mathrm{ng} / \mathrm{mL}$ for Canada or $300 \mathrm{ng} / \mathrm{mL}$ for the United States) and if estimation was at cow level (relevant to both Canada and the United States) or at the bulk tank level (being relevant to the United States only). Overall, when using a high dose of tetracycline $(50 \mathrm{~g} / \mathrm{cow})$, it is likely that tetracycline would be below $100 \mathrm{ng} / \mathrm{mL}$ with a minimum withdrawal interval of 70 $\mathrm{h}$ for milk discard from an individual treated cow. If 1 cow in a 10-cow herd was treated using a maximum of $10 \mathrm{~g}$ of tetracycline per cow, it is likely that tetracycline concentrations at bulk tank level would not exceed 300 $\mathrm{ng} / \mathrm{mL}$ at a milk withdrawal interval of $0 \mathrm{~h}$. In agreement with Gorden et al. (2016), withdrawal interval estimates should be accompanied with residue-screening tests on all treated animals to ensure food safety.

In addition, it is important to highlight that our study's results should not be extrapolated to other antibiotics commonly used for DD treatment, such as lincomycin or chlortetracycline (Berry et al., 2010; Kleinhenz, 2014; Klawitter et al., 2017). To our knowledge, similar studies using those antibiotics have not been carried out. Nevertheless, caution and veterinary involvement to determine appropriate withdrawal intervals should always be used when using antibiotics extra label regardless of route or presentation.

The main limitations of our study include a small sample size (which decreased the power of the study) and not having collected bulk tank milk samples. Despite clear evidence on the presence of detectable and quantifiable tetracycline in individual milk samples, that in some cases reached violative levels, it was not possible to quantify the concentration of tetracycline in the farm's bulk tank.

\section{CONCLUSIONS}

Based on our results, we suggest conservative measures and following appropriate local regulations when using antibiotics topically to treat DD. These measures should include gentle cleaning that does not cause ad- ditional damage to the DD lesion and reducing risks of violative residues in milk by using the lowest effective dose of tetracycline. When these measures are followed, withdrawal intervals for individual cows would be 24 to $36 \mathrm{~h}$ to meet Canadian MRL and $0 \mathrm{~h}$ to meet US tolerances for tetracycline in dairy milk. To ensure appropriate ELDU and meet regional regulatory policies veterinarians should receive guidance from FARAD in the United States and the Canadian Global Food Animal Avoidance Databank in Canada. Furthermore, testing of the milk from individual cows or the bulk tank with a commercial screening test for tetracycline will aid in ensuring food safety.

\section{ACKNOWLEDGMENTS}

The authors thank participating farms for their willingness and time. We are especially grateful for the contributions of Ann Godkin [Ontario Ministry of Agriculture, Food and Rural Affairs (OMAFRA), Elora, ON, Canada], Trisha Dowling (University of Saskatchewan, Saskatoon, SK, Canada), Todd Duffield (University of Guelph, Guelph, ON, Canada), Erin Royster (University of Minnesota, St. Paul, MN), Cleeson Mill (Country Hoof Care, St. Charles, MN), and for contributions of Megan Thompson, Brian Stampfl, Jesse Ingvalson, Gerald Dykstra, Tommy Winders, Michelle Reitsma, Kayla Klehr, Grant Stoddard, and Janna Sorg (University of Minnesota, St. Paul) in data collection. This study was funded by OMAFRA (Guelph, Canada), Dairy Farmers of Ontario (Mississauga, Canada), and Vetoquinol (Lavaltrie, Canada).

\section{REFERENCES}

Al-Mazeedi, H. M., A. B. Abbas, H. F. Alomirah, W. Y. Al-Jouhar, S. A. Al-Mufty, M. M. Ezzelregal, and R. A. Al-Owaish. 2010. Screening for tetracycline residues in food products of animal origin in the State of Kuwait using Charm II radio-immunoassay and LC/MS/MS methods. Food Addit. Contam. Part A Chem. Anal. Control Expo. Risk Assess. 27:291-301. https://doi.org/10.1080/ 19440040903331027.

Anderson, K. L., W. A. Moats, J. E. Rushing, D. P. Wesen, and M. G. Papich. 1995. Potential for oxytetracycline administration by three routes to cause milk residues in lactating cows, as detected by radioimmunoassay (Charm II) and high-performance liquid chromatography test methods. Am. J. Vet. Res. 56:70-77.

Apley, M. D. 2015. Clinical evidence for individual animal therapy for papillomatous digital dermatitis (hairy heel wart) and infectious bovine pododermatitis (foot rot). Vet. Clin. North Am. Food Anim. Pract. 31:81-95. https://doi.org/10.1016/j.cvfa.2014.11 .009 .

Argáez-Rodríguez, F. J., D. W. Hird, J. Hernández De Anda, D. H. Read, and A. Rodríguez-Lainz. 1997. Papillomatous digital dermatitis on a commercial dairy farm in Mexicali, Mexico: Incidence and effect on reproduction and milk production. Prev. Vet. Med. 32:275-286. https://doi.org/10.1016/S0167-5877(97)00031-7.

Baynes, R. E., A. L. Craigmill, and J. E. Riviere. 1997. Residue avoidance after topical application of veterinary drugs and parasiticides. J. Am. Vet. Med. Assoc. 210:1288-1289. 
Berry, S. L., R. Ertze, and D. H. Read. 2004. Field evaluation of prophylactic and therapeutic effects of a vaccine against (papillomatous) digital dermatitis of dairy cattle in two California dairies. Page 147 in Proc. 13th International Symposium on Ruminant Lameness, Maribor, Slovenija. Ungula Zemljič \& Co. D.N.O. Ormož, Slovenia.

Berry, S. L., D. H. Read, T. R. Famula, A. Mongini, and D. Döpfer. 2012. Long-term observations on the dynamics of bovine digital dermatitis lesions on a California dairy after topical treatment with lincomycin $\mathrm{HCl}$. Vet. J. 193:654-658. https://doi.org/10 $.1016 / j . t v j l .2012 .06 .048$.

Berry, S. L., D. H. Read, R. L. Walker, and T. R. Famula. 2010. Clinical, histologic, and bacteriologic findings in dairy cows with digital dermatitis (footwarts) one month after topical treatment with lincomycin hydrochloride or oxytetracycline hydrochloride. J. Am. Vet. Med. Assoc. 237:555-560.

Britt, J. S., M. C. Carson, J. D. von Bredow, and R. J. Condon. 1999. Antibiotic residues in milk samples obtained from cows after treatment for papillomatous digital dermatitis. J. Am. Vet. Med. Assoc. 215:833-836

Cha, E., J. A. Hertl, D. Bar, and Y. T. Grohn. 2010. The cost of different types of lameness in dairy cows calculated by dynamic programming. Prev. Vet. Med. 97:1-8. https://doi.org/10.1016/j .prevetmed.2010.07.011.

Charm Sciences Inc. 2013. Operator's Manual: Charm Tetracycline Test for Raw Commingled Cow Milk. Charm Sciences Inc., Lawrence, MA.

Cramer, G., K. D. Lissemore, C. L. Guard, K. E. Leslie, and D. F. Kelton. 2008. Herd- and cow-level prevalence of foot lesions in Ontario dairy cattle. J. Dairy Sci. 91:3888-3895. https://doi.org/ 10.3168/jds.2008-1135.

Cramer, G., T. Winders, L. Solano, and D. H. Kleinschmit. 2018 Evaluation of agreement among digital dermatitis scoring methods in the milking parlor, pen and hoof trimming chute. J. Dairy Sci. 101:2406-2414.

Cutler, J. H., G. Cramer, J. J. Walter, S. T. Millman, and D. F. Kelton. 2013. Randomized clinical trial of tetracycline hydrochloride bandage and paste treatments for resolution of lesions and pain associated with digital dermatitis in dairy cattle. J. Dairy Sci. 96:7550-7557. https://doi.org/10.3168/jds.2012-6384.

Dairy Farmers of Ontario. 2017. Inhibitor load testing program. Accessed Jul. 30, 2018. https://www.milk.org/Corporate/pdf/ Processors-InhibitorProcedures.pdf.

De Gryze, S., I. Langhans, and M. Vandebroek. 2007. Using the correct intervals for prediction: A tutorial on tolerance intervals for ordinary least-squares regression. Chemom. Intell. Lab. Syst. 87:147-154. https://doi.org/10.1016/j.chemolab.2007.03.002.

DeFrain, J. M., M. T. Socha, and D. J. Tomlinson. 2013. Analysis of foot health records from 17 confinement dairies. J. Dairy Sci. 96:7329-7339. https://doi.org/10.3168/jds.2012-6017.

Dohoo, I., W. Martin, and H. Stryhn. 2009. Veterinary Epidemiologic Research. 2nd ed. VER Inc., Charlottetown, Prince Edward Island, Canada.

Döpfer, D., A. A. H. M. ter Huurne, J. L. Cornelisse, A. J. A. M. van Asten, A. Koopmans, F. A. Meijer, Y. H. Schukken, I. Szakáll W. Klee, and R. B. Bosma. 1997. Histological and bacteriological evaluation of digital dermatitis in cattle, with special reference to spirochaetes and Campylobacter faecalis. Vet. Rec. 140:620-623. https://doi.org/10.1136/vr.140.24.620.

European Medicines Agency and Committe for Medicinal Products for Veterinary Use. 2010. Pharmacologically active substances and their classification regarding maximum residue limits in foodstuffs of animal origin. 2010R0037-EN-12.12.2010-002.001-1. London, UK. Accessed Jul. 30, 2018. https://ec.europa.eu/health//sites/ health/files/files/mrl/mrl_20101212_consol.pdf.

European Medicines Agency and Committe for Medicinal Products for Veterinary Use. 2016. Guideline on approach towards harmonisation of withdrawal periods. EMA/CVMP/SWP/735325/2012. London, UK. Accessed Jul. 30, 2018. http://www.ema.europa.eu/ docs/en_GB/document_library/Scientific_guideline/2016/07/ WC500210929.pdf.
Fajt, V. R., and M. D. Apley. 2001. Antimicrobial issues in bovine lameness. Vet. Clin. North Am. Food Anim. Pract. 17:159-173. (vii.).

FARAD. 2018. Withdrawal interval (WDI) recommendations. Accessed Jul. 30, 2018. http://www.farad.org/wdilookup/.

Fritz, J. W., and Y. Zuo. 2007. Simultaneous determination of tetracycline, oxytetracycline, and 4-epitetracycline in milk by highperformance liquid chromatography. Food Chem. 105:1297-1301. https://doi.org/10.1016/j.foodchem.2007.03.047.

Gomez, A., N. B. Cook, N. D. Bernardoni, J. Rieman, A. F. Dusick, R. Hartshorn, M. T. Socha, D. H. Read, and D. Döpfer. 2012. An experimental infection model to induce digital dermatitis infection in cattle. J. Dairy Sci. 95:1821-1830. https://doi.org/10.3168/jds .2011-4754

Gomez, A., N. B. Cook, M. T. Socha, and D. Dopfer. 2015. Firstlactation performance in cows affected by digital dermatitis during the rearing period. J. Dairy Sci. 98:4487-4498. https://doi.org/10 $.3168 /$ jds.2014-9041.

Gorden, P. J., J. A. Ydstie, M. D. Kleinhenz, L. W. Wulf, R. Gehring, C. J. Lee, C. Wang, and J. F. Coetzee. 2016. A study to examine the relationship between metritis severity and depletion of oxytetracycline in plasma and milk after intrauterine infusion. J. Dairy Sci. 99:8314-8322. https://doi.org/10.3168/jds.2016-10959.

Health Canada and Veterinary Drugs Directorate. 2008. Policy on extra-label drug use (ELDU) in food producing animals. Government of Canada, Drugs and Health Products, Veterinary Drugs, Extra-label drug use (ELDU) in animals. Accessed Jul. 30, 2018. https://www.canada.ca/en/health-canada/services/drugs-health -products/veterinary-drugs/extra-label-drug-use/policy-extra -label-drug-use-eldu-food-producing-animals.html.

Health Canada and Veterinary Drugs Directorate. 2017. List of maximum residue limits (MRLs) for veterinary drugs in foods. Government of Canada, Drugs and Health Products, Veterinary Drugs, Maximum Residue Limits. Accessed Jul. 30, 2018. https://www .canada.ca/en/health-canada/services/drugs-health-products/ veterinary-drugs/maximum-residue-limits-mrls/list-maximum -residue-limits-mrls-veterinary-drugs-foods.html.

Hernandez, J., and J. K. Shearer. 2000. Efficacy of oxytetracycline for treatment of papillomatous digital dermatitis lesions on various anatomic locations in dairy cows. J. Am. Vet. Med. Assoc. 216:1288-1290. https://doi.org/10.2460/javma.2000.216.1288.

Holzhauer, M., C. J. Bartels, M. van Barneveld, C. Vulders, and T. Lam. 2011. Curative effect of topical treatment of digital dermatitis with a gel containing activated copper and zinc chelate. Vet. Rec. 169:555. https://doi.org/10.1136/vr.d5513.

Kang, J. H., J. H. Jin, and F. Kondo. 2005. False-positive outcome and drug residue in milk samples over withdrawal times. J. Dairy Sci. 88:908-913. https://doi.org/10.3168/jds.S0022-0302(05)72757-0.

Klawitter, M., D. Döpfer, E. Amene, T. Braden, and K. E. Müller. 2017. To bandage or not bandage: The curative effect of bandaging digital dermatitis lesions. Pages 48-49 in Proc. 19th International Symposium and 11th Conference of Lameness in Ruminants, Munich, Germany. Conference GBR, Rosenheim, Germany.

Kleinhenz, K. E., P. J. Plummer, J. Danielson, R. G. Burzette, P. J. Gorden, J. Coetzee, J. A. Schleining, V. Cooper, B. Leuschen, A. Krull, L. Shearer, and J. K. Shearer., 2014. Survey of veterinarians and hoof trimmers on methods applied to treat claw lesions in dairy cattle. Bov. Pract. 48:47-52.

Krull, A. C., V. L. Cooper, J. W. Coatney, J. K. Shearer, P. J. Gorden, and P. J. Plummer. 2016b. A highly effective protocol for the rapid and consistent induction of digital dermatitis in Holstein calves. PLoS One 11:e0154481. https://doi.org/10.1371/journal pone. 0154481.

Krull, A. C., J. K. Shearer, P. J. Gorden, H. M. Scott, and P. J. Plummer. 2016a. Digital dermatitis: Natural lesion progression and regression in Holstein dairy cattle over 3 years. J. Dairy Sci. 99:3718-3731. https://doi.org/10.3168/jds.2015-10535.

Manske, T., J. Hultgren, and C. Bergsten. 2002. Topical treatment of digital dermatitis associated with severe heel-horn erosion in a Swedish dairy herd. Prev. Vet. Med. 53:215-231. 
Martin-Jimenez, T., A. L. Craigmill, and J. E. Riviere. 1997. Extralabel use of oxytetracycline. J. Am. Vet. Med. Assoc. 211:42-44.

Martinez, M., L. Friedlander, R. Condon, J. Meneses, J. O'Rangers, N. Weber, and M. Miller. 2000. Response to criticisms of the US FDA parametric approach for withdrawal time estimation: rebuttal and comparison to the nonparametric method proposed by Concordet and Toutain. J. Vet. Pharmacol. Ther. 23:21-35. https://doi.org/ 10.1046/j.1365-2885.2000.00242.x.

Mesgari Abbasi, M., H. Babaei, M. Ansarin, A. O. Nourdadgar, and M. Nemati. 2011. Simultaneous determination of tetracyclines residues in bovine milk samples by solid phase extraction and HPLCFL method. Adv. Pharm. Bull. 1:34-39. https://doi.org/10.5681/ apb.2011.005.

Moore, D. A., S. L. Berry, M. L. Truscott, and V. Koziy. 2001. Efficacy of a nonantimicrobial cream administered topically for treatment of digital dermatitis in dairy cattle. J. Am. Vet. Med. Assoc. 219:1435-1438.

National Conference on Interstate Milk Shipments. 2017. NCIMS Appendix N Pilot Program. Accessed Jul. 30, 2018. http://ncims .org/programs/appendix-n-pilot-program/.

Oliveira, V. H. S., J. T. Sørensen, and P. T. Thomsen. 2017. Associations between biosecurity practices and bovine digital dermatitis in Danish dairy herds. J. Dairy Sci. 100:8398-8408. https://doi.org/ 10.3168/jds.2017-12815.

Plummer, P. J., and A. Krull. 2017. Clinical perspectives of digital dermatitis in dairy and beef cattle. Vet. Clin. North Am. Food Anim. Pract. 33:165-181. https://doi.org/10.1016/j.cvfa.2017.02.002.

Relun, A., A. Lehebel, A. Chesnin, R. Guatteo, and N. Bareille. 2013. Association between digital dermatitis lesions and test-day milk yield of Holstein cows from 41 French dairy farms. J. Dairy Sci. 96:2190-2200. https://doi.org/10.3168/jds.2012-5934.

Riviere, J. E., A. I. Webb, and A. L. Craigmill. 1998. Primer on estimating withdrawal times after extralabel drug use. J. Am. Vet. Med. Assoc. 213:966-968.

Rodrigues, C. A., C. A. Hussni, E. S. Nascimento, C. Esteban, and S. H. V. Perri. 2010. Pharmacokinetics of tetracycline in plasma, synovial fluid and milk using single intravenous and single intravenous regional doses in dairy cattle with papillomatous digital dermatitis. J. Vet. Pharmacol. Ther. 33:363-370. https://doi.org/ 10.1111/j.1365-2885.2009.01138.x.

Sischo, W. M. 1996. Quality milk and tests for antibiotic residues. J. Dairy Sci. 79:1065-1073. https://doi.org/10.3168/jds.S0022 -0302(96)76460-3.
Solano, L., H. W. Barkema, S. Mason, E. A. Pajor, S. J. LeBlanc, and K. Orsel. 2016. Prevalence and distribution of foot lesions in dairy cattle in Alberta, Canada. J. Dairy Sci. 99:6828-6841. https://doi .org/10.3168/jds.2016-10941.

US Food and Drug Administration. 2010. 21 CFR 530: Extralabel Drug Use of FDA Approved Drugs in Animals. e-CFR, Title 21: Food and Drugs, Chp 1, Subchp E, Part 530. Accessed Jul. 30, 2018. https://www.fda.gov/AnimalVeterinary/ GuidanceComplianceEnforcement/ActsRulesRegulations/ ucm085377.htm.

US Food and Drug Administration and Center for Veterinary Medicine. 2015. Studies to evaluate the metabolism and residue kinetics of veterinary drugs in food-producing animals: Marker residue depletion studies to establish product withdrawal periods. Accessed Jul. 30, 2018. https://www.fda.gov/downloads/AnimalVeterinary/ GuidanceComplianceEnforcement/GuidanceforIndustry/ UCM207941.pdf.

US Food and Drug Administration and Center for Veterinary Medicine. 2016. CVM Guidance for Industry (GFI) \#3: General principles for evaluating the human food safety of new animal drugs used in foodproducing animals. Accessed Jul. 30, 2018. https://www.fda.gov/ downloads/AnimalVeterinary/GuidanceComplianceEnforcement/ GuidanceforIndustry/ucm052180.pdf.

USDA. 2009. Dairy 2007, Part IV: Reference of dairy cattle health and management practices in the United States. USDA:APHIS: VS, CEAH. Fort Collins, CO. \#N494.0209. Accessed Jul. 30, 2018. https://www.fda.gov/downloads/AnimalVeterinary/ GuidanceComplianceEnforcement/GuidanceforIndustry/ UCM207941.pdf.

Wilson-Welder, J., D. Alt, and J. Nally. 2015. Digital dermatitis in cattle: current bacterial and immunological findings. Animals (Basel) 5:1114-1135.

World Health Organization. 2015. Maximum residue limits (MRLs) and risk management recommendations (RMRs) for residues of veterinary drugs in foods. Codex Alimentarius Commission, WHO Technical Report Series; 38th session. Accessed Jul. 30, 2018. www .fao.org/input/download/standards/45/MRL2_2015e.pdf.

Zinicola, M., F. Lima, S. Lima, V. Machado, M. Gomez, D. Döpfer, C. Guard, and R. Bicalho. 2015. Altered microbiomes in bovine digital dermatitis lesions, and the gut as a pathogen reservoir. PLoS One 10:e0120504. https://doi.org/10.1371/journal.pone.0120504. 